\title{
XRD STUDY OF COBALT [Co(II)] COMPLEXES SYNTHESIZED WITH LIGANDS OF ANILINE/TOLUIDINE DITHIOCARBAMATE
}

\author{
Anurag Geete ${ }^{1, *}$, B. D. Shrivastava ${ }^{2}$ and Ashutosh Mishra ${ }^{3}$ \\ ${ }^{1}$ Department of Physics, SRGBN College, Sanawad, Khargone- \\ 451111, Madhya Pradesh, India \\ ${ }^{2}$ Maharaja Bhoj Govt. P. G. College, Dhar-454001, INDIA \\ ${ }^{3}$ School of Physics, Devi Ahilya University, Indore-452001, INDIA \\ *E-mail: anuraggeete.21@gmail.com
}

\begin{abstract}
In the present investigation, seven cobalt [Co(II)] complexes were synthesized using various ligands of Aniline/Toluidine dithiocarbamate. The synthesized Co(II) complexes were studied for different structural and chemical parameters using XRD. The output obtained from X-ray studies was synthesized using Athena and Origin 6.0 software. The results of the investigation were used in determining the structures of the synthesized complexes. The results of the study revealed that the particle size of synthesized cobalt complexes ranged between 39.7 and $117.3 \mathrm{~nm}$. The lattice constant of $\mathrm{Co}(\mathrm{II})$ complexes was found 7.57-10.57 $\AA$. The synthesized Co(II) metal complexes behaved as symmetric bidentate ligand during complexation and carry no charge and were found thermally stable.
\end{abstract}

Keywords: Aniline, Toluidine, Dithiocarbamate, Co(II) Complex, Ligands, XRD

(C) RASĀYAN. All rights reserved

\section{INTRODUCTION}

Cobalt is a chemical element with the symbol Co and atomic number $27 .{ }^{1}$ Like nickel, cobalt is found in the Earth's crust only in chemically combined form, save for small deposits found in alloys of natural meteoric iron. ${ }^{2}$ The free element, produced by reductive smelting, is a hard, lustrous, silver-gray metal. Cobalt is a weakly reducing metal that is protected from oxidation by a passivating oxide film. It is attacked by halogens and sulfur. As for all metals, molecular compounds and polyatomic ions of cobalt are classified as coordination complexes, that is, molecules or ions that contain cobalt linked to several ligands. ${ }^{3-5}$ The principles of electronegativity and hardness-the softness of a series of ligands can be used to explain the usual oxidation state of cobalt. ${ }^{6}$ For example, $\mathrm{Co}^{+3}$ complexes tend to have ammine ligands. Cobalt is essential to the metabolism of all animals. It is a key constituent of cobalamin, also known as vitamin B12, the primary biological reservoir of cobalt as an ultra trace element. ${ }^{7}$ Bacteria in the stomachs of ruminant animals convert cobalt salts into vitamin B12, a compound which can only be produced by bacteria or archaea. A minimal presence of cobalt in soils therefore markedly improves the health of grazing animals, and an uptake of $0.20 \mathrm{mg} / \mathrm{kg}$ a day is recommended because they have no other source of vitamin B12. ${ }^{8-9}$ Proteins based on cobalamin use corrin to hold the cobalt. Coenzyme B12 features a reactive $\mathrm{C}$-Co bond that participates in the reactions. In humans, B12 has two types of alkyl ligand: methyl and adenosyl. MeB12 promotes methyl $\left(-\mathrm{CH}_{3}\right)$ group transfers. The adenosyl version of B12 catalyzes rearrangements in which a hydrogen atom is directly transferred between two adjacent atoms with concomitant exchange of the second substituent, $\mathrm{X}$, which may be a carbon atom with a substituent, an oxygen atom of an alcohol, or an amine. Methylmalonyl coenzyme A mutase (MUT) converts MMlCoA to Su-CoA, an important step in the extraction of energy from proteins and fats. ${ }^{10}$ Although far less common than other metalloproteins (e.g. those of zinc and iron), other cobaltoproteins are known besides B12. These proteins include methionine aminopeptidase 2, an enzyme that occurs in humans and other

Rasayan J. Chem., 13(3), 1878-1884(2020)

http://dx.doi.org/10.31788/ RJC.2020.1335777

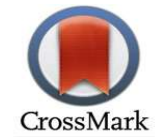


mammals that does not use the corrin ring of B12, but binds cobalt directly. Another non-corrin cobalt enzyme is nitrile hydratase, an enzyme in bacteria that metabolizes nitriles. ${ }^{11}$

Dithiocarbamates, the half amides of dithiocarbonic acids, was discovered as a class of chemical compounds in the history of organosulfur chemistry. These are a versatile class of monoanionic 1,1-dithio ligands and as they are easily prepared, a wide range of chemistry has been developed around them ${ }^{12-14}$. Complexes of dithiocarbamate ligands like dithiocarbamate themselves have practical application in agriculture and for treatment of alcoholism ${ }^{15-16}$ recently gold (III) dithiocarbamate complexes have been prepared and used for the treatment of human cancer by suppressing tumor growth via direct inhibition of the proteasome activity. ${ }^{17}$ Complexes of transition metals with mixed ligands, $\mathrm{S}$ and $\mathrm{N}$ as donor atoms have found great interest among other coordination complexes. ${ }^{18-20}$ Considering these facts, the present study was conducted to synthesize the Co(II) complexes with aniline/toluidine dithiocarbamate ligands and their properties were studied using the XRD technique.

\section{Preparation of Ligands}

\section{EXPERIMENTAL}

In the present investigation, Chloroaniline dithiocarbamate ${ }^{21}$, Nitroaniline dithiocarbamate ${ }^{22}$, Fluoroaniline dithiocarbamate $\mathrm{e}^{23}$ and Toluidine dithiocarbamate ${ }^{24}$ ligands were synthesized and used as a complexing agent for $\mathrm{Co}(\mathrm{II})$. The ligands were prepared by adding $0.01 \mathrm{M}$ of aniline/toluidine to $0.016 \mathrm{M}$ solution of $\mathrm{NaOH}$ in $15 \mathrm{ml}$ distilled water with continuous stirring. The mixture was refluxed for two hours and further, it was cooled in ice. The ligands were precipitated by the dropwise addition of carbon disulphide. The formed ligands were extracted by ether, filtered, washed with acetone and dried in vacuum. ${ }^{21-24}$

\section{Synthesis of Co (II) Complexes}

The cobalt $[\mathrm{Co}(\mathrm{II})]$ complexes with synthesized ligands were prepared by mixing 1:2 molar quantities of metal salt and ligand. The cobalt chloride salt $\left(\mathrm{CoCl}_{2}\right)$ was dissolved in distilled water and ligand aniline / toluidine dithiocarbamate was dissolved in ethanol..$^{21-22}$ The two solutions were mixed with continuous stirring. The complex produced in the form of precipitate was filtered off, washed with acetone and water in equal quantities (1:1). The product was dried in vacuum. ${ }^{23-24}$ The fine powder of the formed complexes was used for further analytical studies.

\section{XRD Studies}

The XRD measurements were obtained by using the Bruker D8 Advance X-ray diffractometer. Monochromatic X-rays, in an exceedingly narrow, well-collimated beam were used. The X-rays were created employing a sealed tube and the wavelength of X-rays was $1.54 \AA .^{25}$ The study was carried out at UGC-DAE Consortium for Scientific Research, Indore (M.P.). The results from all the samples of cobalt were interpreted using Origin 6.0 software.

\section{Determination of Lattice Constants $(\AA)$}

The lattice constants were determined using Bragg's equation for all the complexes synthesized. ${ }^{26-27}$ Bragg's equation used is as follows:

$$
\begin{aligned}
& \qquad \mathrm{d} \sin \theta=\mathrm{n} \lambda \\
& \text { Where } \mathrm{d} \text { is the interplanar distance and calculated as } d=\frac{a}{\sqrt{h^{2}+l^{2}+k^{2}}}
\end{aligned}
$$

$\theta$ is the incident angle;

$\mathrm{n}$ is a positive integer;

$\lambda$ is the wavelength of incident radiation and

$h, k$ and $l$ are the Miller Indices.

\section{Determination of Particle Size (nm)}

The particle size of all the complexes was determined using the Scherrer's equation as follows ${ }^{28-29}$ :

$$
\tau=\frac{K \lambda}{\beta \operatorname{Cos} \theta}
$$


Where,

$\tau$ is the particle size;

$\mathrm{K}$ is the dimentionless shape factor;

$\lambda$ is the wavelength of incident radiation;

$\beta$ is the line broadening at half the maximum intensity and

$\theta$ is the Bragg angle.

\section{RESULTS AND DISCUSSION}

\section{XRD Studies of Cobalt [Co(II)] Complexes}

The details of synthesized cobalt [Co(II)] complexes with prepared ligands of aniline/toluidine dithiocarbamate ${ }^{30}$ is presented in Table-1. Seven different complexes of cobalt [Co(II)] were synthesized using aniline/toluidine dithiocarbamate ligands following the standard methods. ${ }^{21-24}$ Out of seven ligands, three were synthesized with nitroaniline dithicarbamate ligand ${ }^{21}$, two were with chloroaniline dithicarbamate $^{22}$ and each one was formed using toluidine dithicarbamate ${ }^{23}$ and fluoroaniline dithicarbamate ${ }^{24}$ (Table-1).

Table-1: Details of Cobalt [Co(II)] Mixed Ligand Complexes

\begin{tabular}{c|c|c}
\hline Abbreviation & Complex Name & Molecular Formula \\
\hline Co-1 & Co(o-Nitroaniline dithiocarbamate $)_{2}$ & $\mathrm{Co}\left(\mathrm{C}_{7} \mathrm{H}_{4} \mathrm{~N}_{2} \mathrm{~S}_{2} \mathrm{O}_{2}\right)_{2}$ \\
\hline Co-2 & $\mathrm{Co}(\text { p-Nitroaniline dithiocarbamate })_{2}$ & $\mathrm{Co}\left(\mathrm{C}_{7} \mathrm{H}_{4} \mathrm{~N}_{2} \mathrm{~S}_{2} \mathrm{O}_{2}\right)_{2}$ \\
\hline Co-3 & $\mathrm{Co}(\text { m-Nitroaniline dithiocarbamate })_{2}$ & $\mathrm{Co}\left(\mathrm{C}_{7} \mathrm{H}_{4} \mathrm{~N}_{2} \mathrm{~S}_{2} \mathrm{O}_{2}\right)_{2}$ \\
\hline Co-4 & $\mathrm{Co}(\mathrm{o} \text {-Chloroaniline dithiocarbamate })_{2}$ & $\mathrm{Co}\left(\mathrm{C}_{7} \mathrm{H}_{4} \mathrm{~S}_{2} \mathrm{NCl}\right)_{2}$ \\
\hline Co-5 & $\mathrm{Co}(\text { p-Chloroaniline dithiocarbamate })_{2}$ & $\mathrm{Co}\left(\mathrm{C}_{7} \mathrm{H}_{4} \mathrm{~S}_{2} \mathrm{NCl}\right)_{2}$ \\
\hline Co-6 & Co $(4 \text {-Fluoroaniline dithiocarbamate })_{2}$ & $\mathrm{Co}\left(\mathrm{C}_{7} \mathrm{H}_{4} \mathrm{~S}_{2} \mathrm{NF}_{2}\right.$ \\
\hline Co-7 & Co(p-Toluidine dithiocarbamate $)_{2}$ & $\mathrm{Co}\left(\mathrm{C}_{8} \mathrm{H}_{7} \mathrm{NS}_{2}\right)_{2}$ \\
\hline
\end{tabular}

The formed cobalt $[\mathrm{Co}(\mathrm{II})]$ complexes were processed like washing and drying, grinding and mixing to yield a homogenous powder. The thoroughly mixed and ground dry powder complexes were used for XRD studies.

\section{XRD Pattern of Cobalt Complexes}

All seven cobalt $[\mathrm{Co}(\mathrm{II})]$ complexes synthesized were studied and characterized at room temperature. ${ }^{25}$ For this purpose, the Co $\mathrm{K} \alpha$ radiation was used during the XRD investigation. The XRD pattern of $2 \theta$ ranging between $10^{\circ}$ and $60^{\circ}$ were recorded. The indexing of the XRD pattern was carried out using the Joint Committee for Powder diffraction optical phenomenon computer code (JCPDF). The lattice constants $(\AA)$ and particle size $(\mathrm{nm})$ of cobalt [Co(II)] complexes synthesized with ligands of aniline/toluidine dithiocarbamate were determined using Bragg's equation and Scherrer's equation, respectively. The X-ray diffraction patterns of the synthesized cobalt complexes are presented in Fig.-1.

\section{The Particle Size of Co(II) Complexes}

The particle of the Co(II) complexes was determined from the XRD pattern employing the Scherrer's equation. ${ }^{26-27}$ The particle size of the various cobalt complexes under study is presented in Table- 2 .

Table-2: Particle Size and Lattice Constant of Synthesized Cobalt [Co(II)] Complexes

\begin{tabular}{c|c|c|c}
\hline Abbreviation & Co(II) Complex & Particle Size $(\mathrm{nm})$ & Lattice Constant $(\AA)$ \\
\hline Co-1 & $\mathrm{Co}(\mathrm{o}-\text { Nitroaniline dithiocarbamate })_{2}$ & 71.1 & 10.57 \\
\hline Co-2 & $\mathrm{Co}(\mathrm{p}-\text { Nitroaniline dithiocarbamate })_{2}$ & 52.2 & 7.97 \\
\hline Co-3 & $\mathrm{Co}(\mathrm{m} \text {-Nitroaniline dithiocarbamate })_{2}$ & 39.7 & 9.86 \\
\hline Co-4 & $\mathrm{Co}(\mathrm{o}-\text {-Chloroanilinedithiocarbamate })_{2}$ & 59.1 & 8.67 \\
\hline Co-5 & $\mathrm{Co}(\mathrm{p} \text {-chloroanilinedithiocarbamate })_{2}$ & 117.3 & 8.28 \\
\hline Co-6 & $\mathrm{Co}(4 \text {-Floroaniline dithiocarbamate })_{2}$ & 60.4 & 8.34 \\
\hline Co-7 & $\mathrm{Co}(\text { p-Toludinedithiocarbamate })_{2}$ & 75.6 & 7.57 \\
\hline
\end{tabular}

The particle size of Co(II) complexes ranged between $39.7 \mathrm{~nm}$ and $117.3 \mathrm{~nm}$. The highest particle size of $117.3 \mathrm{~nm}$ was observed for the cobalt complex synthesized using $\mathrm{p}$-Chloroaniline dithiocarbamate (Co-5) 
RASĀYAN J. Chem.

Vol. 13 | No. 3 |1878-1884| July - September | 2020

whereas the lowest particle size was recorded for Co-3 complex [Co(m-Nitroaniline dithiocarbamate $)_{2}$. The cobalt complexes followed the below trend concerning the particle size:

$$
\text { Co- } 5>\text { Co- } 7>\text { Co- } 1>\text { Co- } 6>\text { Co- } 4>\text { Co- } 2>\text { Co- } 3
$$

The synthesized cobalt complexes showed a noticeable difference in particle size due to the nature and position of the ligand and ligand forming group, respectively (Table-2). The earlier reported works conform with present findings. ${ }^{31-36}$
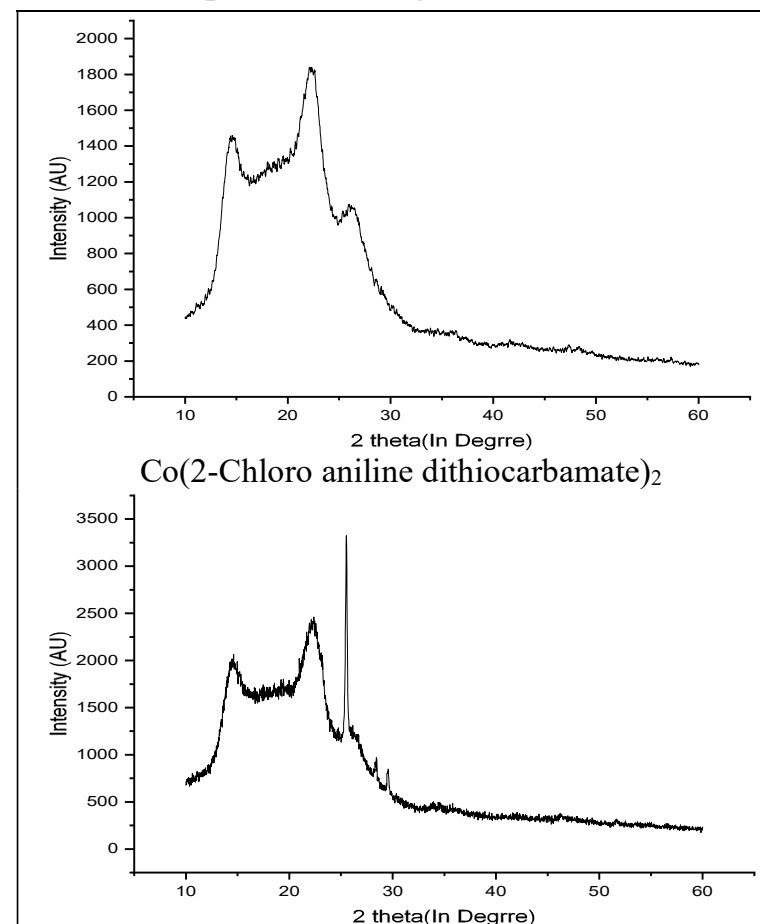

$\operatorname{Co}(3-N i t r o \text { aniline dithiocarbamate })_{2}$

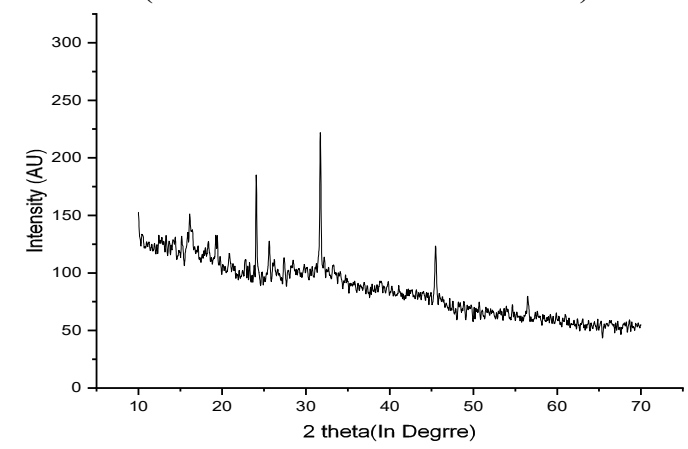

$\mathrm{Co}(4-\mathrm{Nitro} \text { aniline dithiocarbamate })_{2}$

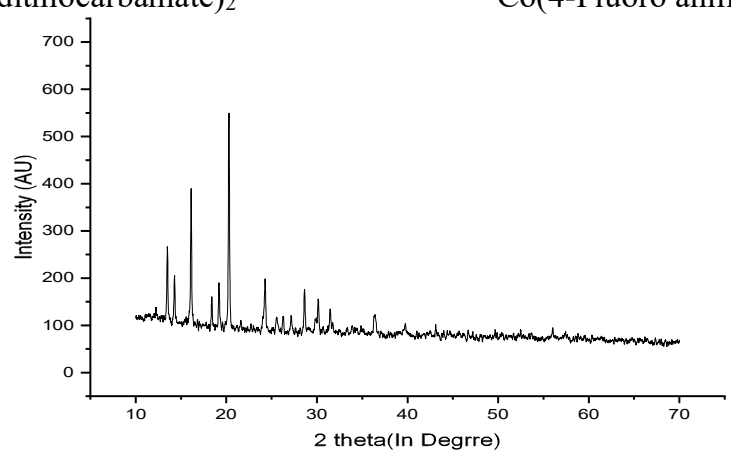

$\mathrm{Co}(\mathrm{p} \text {-toluidine dithiocarbamate })_{2}$

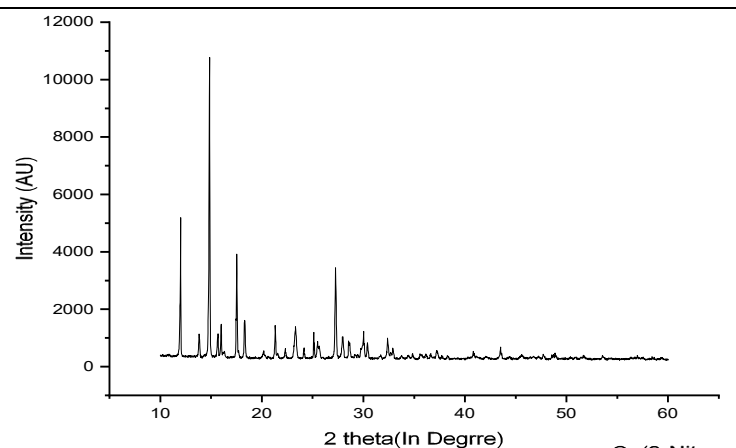

$\mathrm{Co}(2-\mathrm{Nitro} \text { aniline dithiocarbamate })_{2}$

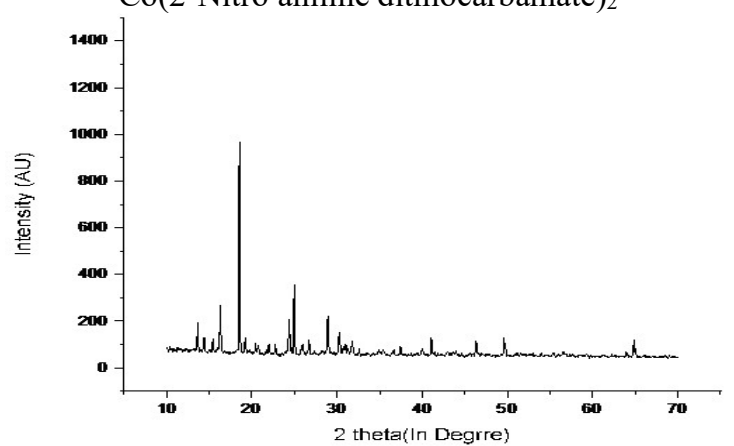

Co(4-Chloro aniline dithiocarbamate $)_{2}$

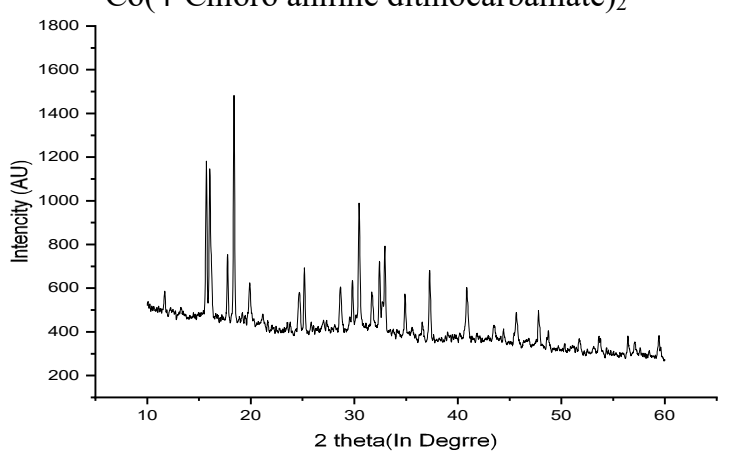

$\mathrm{Co}(4-F l u o r o \text { aniline dithiocarbamate })_{2}$

Fig.-1: XRD Pattern of Synthesized Cobalt [Co(II)] Complexes 
RASĀYAN J. Chem.

Vol. 13 | No. 3 |1878-1884| July - September | 2020

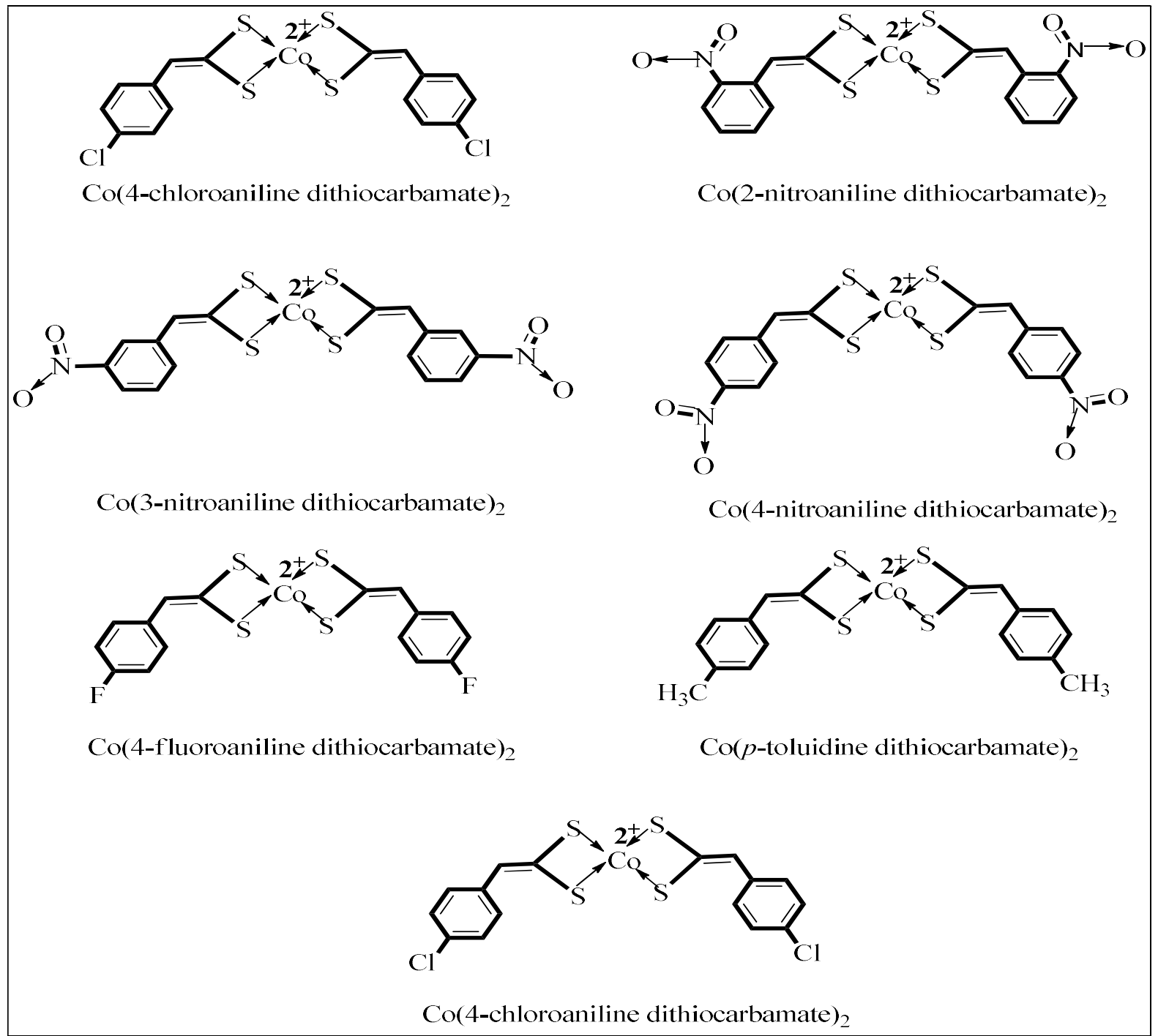

Fig.-2: Suggested Structures of Synthesized Cobalt [Co(II)] Complexes

The Lattice Constant of Co(II) Complexes

The lattice constant of the Co(II) complexes was determined from the XRD pattern employing the Bragg's equation. ${ }^{28-29}$ The Lattice constant for various cobalt complexes under study is presented in Table-2. The Lattice constant of $\mathrm{Co}$ (II) complexes ranged between $7.57 \AA$ and $10.57 \AA$. The cobalt complex synthesizes using o-Nitroaniline dithiocarbamate(Co-1) showed the highest Lattice constant whereas the $\mathrm{Co}$ (II) complexed formed with $\mathrm{p}$-Toluidine dithiocarbamate $(\mathrm{Co}-7)$ recorded the lowest value of Lattice constant. The cobalt complexes followed the below trend concerning the Lattice constant:

$$
\mathrm{Co}-1>\mathrm{Co}-3>\mathrm{Co}-4>\mathrm{Co}-6>\mathrm{Co}-5>\mathrm{Co}-2>\mathrm{Co}-7
$$

The synthesized cobalt complexes showed a noticeable difference in Lattice constant due to the nature and position of ligand and ligand forming group, respectively (Table 2). The earlier reported works conform with present findings. ${ }^{31-36}$

\section{Structures of Synthesized Cobalt [Co(II)] Complexes}

Based on the X-ray diffraction studies, particle size and lattice constant of the obtained Co(II) complexes the structures for the same were suggested. Considering the chemistry of reactants, ligands and cobalt (II) ion and obtained results of complexes, the suggested structures are presented in Fig.-2. The earlier reported works conform with present findings. ${ }^{31-36}$ 
RASĀYAN J. Chem.

Vol. 13 | No. 3 |1878-1884| July - September | 2020

\section{Suggested Structures of Co(II) Complexes}

Based upon the XRD investigation of the synthesized $\mathrm{Co}$ (II) metal complexes with aniline/toluidine dithiocarbamate, the structures of the complexes have been suggested and presented in Fig.-2. In all the complexes, cobalt $\mathrm{Co}^{++}$ion occupied central position forming bonds with sulfur.

\section{CONCLUSION}

The seven cobalt $[\mathrm{Co}(\mathrm{II})]$ complexes synthesized using various Aniline/Toluidine dithiocarbamate ligands. The XRD investigation of seven cobalt [Co(II)] complexes revealed that, the particle size of synthesized complexes ranged between 39.7 and $117.3 \mathrm{~nm}$. The lattice constant of Co(II) complexes was found 4.33-4.92 ̊. The synthesized Co(II) metal complexes behaved as symmetric bidentate ligand during complexation and carry no charge and were found thermally stable.

\section{REFERENCES}

1. W. Betteridge, Progress in Materials Science, 24, 51(1980), DOI:10.1016/0079-6425(79)90004-5

2. P.F. Woolrich, American Industrial Hygiene Association Journal, 34(5), 217(1973), DOI: $10.1080 / 0002889738506837$

3. T. Ohtsuka and N. Sato, Journal of The Electrochemical Society, 128(12), 2522(1981), DOI: $10.1149 / 1.2127284$

4. R.J. Cozens, G.B. Deacon, P.W. Felder, K.S. Murray and B.O. West, Australian Journal of Chemistry, 23(3), 481(1970), DOI:10.1071/CH9700481

5. F.A. Cotton and J.G. Bergman, Journal of the American Chemical Society, 86(14), 2941(1964), DOI: $10.1021 / \mathrm{ja} 01068 \mathrm{a} 040$

6. J.G. Dillard, D.L. Crowther and J.W. Murray, Geochimica et Cosmochimica Acta, 46(5), 755(1982), DOI: $10.1016 / 0016-7037(82) 90027-8$

7. S.H. Kim, H.L. Chen, N. Feilchenfeld and J. Halpern, Journal of the American Chemical Society, 110(10), 3120(1988), DOI:10.1021/ja00218a021

8. H.L. Schubert, K.S. Wilson, E. Raux, S.C. Woodcock and M.J. Warren, Nature Structural \& Molecular Biology, 5(7), 585(1998), DOI:10.1038/846

9. E. Raux, H.L. Schubert and M.J. Warren, Cellular and Molecular Life Sciences, 57(13-14), 1880(2000), DOI:10.1007/PL00000670

10. K. Amininia, A. Rezaeisaber and A. Rezaie, Life Science Journal, 10,558(2013)

11. G.W. McCommon, F. Lochner, A.C.B. Jr and H.E. Young, Autocoids, 2, 103(2013), DOI: $10.4172 / 2161-0479.1000103$

12. R.M. Michaels, L.J. Peterson and G.L. Stahl, Journal of Pharmacy and Pharmacology, 15(1), 107(1963), DOI:10.1111/j.2042-7158.1963.tb12754.x

13. A. Hulanicki, Talanta, 14(12), 1371(1967), DOI:10.1016/0039-9140(67)80159-0

14. G. Hogarth, Progress in Inorganic Chemistry, 53, 471(2005), DOI:10.1002/0471725587.ch2

15. N.K. Kaushik, B. Bhushan and A.K. Sharma, Transition Metal Chemistry, 9(7), 250(1984), DOI: $10.1007 / \mathrm{BF} 00624466$

16. T.M. Kitson, Biochemistry, 25(16), 4718(1986), DOI:10.1021/bi00364a040

17. V. Milacic, D. Chen, L. Ronconi, K.R. Landis-Piwowar, D. Fregona and Q.P. Dou, Cancer Research, 66(21), 10478(2006), DOI:10.1158/0008-5472.CAN-06-3017

18. A.J. Blake, L.M. Gilby, R.O. Gould, V. Lippolis, S. Parsons and M. Schröder, Acta Crystallographica Section C: Crystal Structure Communications, 54(3), 295(1998), DOI: $10.1107 / \mathrm{S} 0108270197014212$

19. B. Kersting, Zeitschrift für Naturforschung B, 55(10), 961(2000), DOI:10.1515/znb-2000-1012

20. I. Gürol, V. Ahsen and Ö. Bekâroğlu, Journal of the Chemical Society, Dalton Transactions, 14, 2283(1992), DOI: 10.1039/DT9920002283

21. J. Iqbal, S.A. Tirmizi, F.H. Wattoo, M. Imran, M.H.S. Watto, S. Sharfuddin and S. Latif, Turkish Journal of Biology, 30(1), 1(2006)

22. A.D. Khalaji, M. Nikookar and D. Das, Journal of Thermal Analysis and Calorimetry, 115(1), 409(2014), DOI: 10.1007/s10973-013-3252-7 
RASĀYAN J. Chem.

Vol. 13 | No. 3 |1878-1884| July - September | 2020

23. C. Chachaty, A. Forchioni and J. Virlet, Canadian Journal of Chemistry, 53(5), 648(1975), DOI: $10.1139 / \mathrm{v} 75-092$

24. C. Engelter, D.A. Thornton and M.R. Ziman, Journal of Molecular Structure, 49(1), 7(1978), DOI: $10.1016 / 0022-2860(78) 87002-1$

25. B.K. Mehta, M. Chhajlani and B.D. Shrivastava, Journal of Physics: Conference Series,836(1), 012050(2017), DOI:10.1088/1742-6596/836/1/012050

26. R. Delhez, T.H. De Keijser and E.J. Mittemeijer, Fresenius' Zeitschrift Für Analytische Chemie, 312(1), 1(1982), DOI:10.1007/BF00482725

27. G.E.M. Jauncey, Proceedings of the National Academy of Sciences of the United States of America, 10(2), 57(1924), DOI: 10.1073/pnas.10.2.57

28. L.S. Birks and H. Friedman, Journal of Applied Physics, 17(8), 687(1946), DOI:10.1063/1.1707771

29. A. Monshi, M.R. Foroughi and M.R. Monshi, World Journal of Nano Science and Engineering, 2(3), 154(2012), DOI: 10.4236/wjnse.2012.23020

30. R. Van Grieken and A. Markowicz eds., 2001, Handbook of X-ray Spectrometry, CRC press.

31. A. Mishra, A. Yadav, S. Ninama and A. Trivedi, Journal of Physics: Conference Series, 365(1), 012020(2012), DOI:10.1088/1742-6596/365/1/012020

32. A. Geete, B. D. Shrivastava and A. Mishra, Asian Journal of Chemistry, 32(3), 627(2020), DOI: 10.14233 /ajchem.2020.22456

33. A. Mishra, A. Yadav, S. Ninama and A. Trivedi, Journal of Physics: Conference Series, 365(1), 012020(2012), DOI:10.1088/1742-6596/365/1/012020

34. J. F. Marco, J. R. Gancedo, M. Gracia, J. L. Gautier, E. Rios and F.J. Berry, Journal of Solid State Chemistry, 153(1), 74(2000), DOI:10.1006/jssc.2000.8749

35. P. K. Malviya, P. Sharma and A. Mishra, International Journal of Scientific Research in Physics and Applied Sciences, 2(1), 1(2014)

36. A. Mishra, S. Ninama and N. Mishra, AIP Conference Proceedings, 1447(1), 163(2012), DOI: $10.1063 / 1.4709931$

[RJC-5777/2020] 